Published in final edited form as:

Calcif Tissue Int. 2014 December ; 95(6): 495-505. doi:10.1007/s00223-014-9917-9.

\title{
Osteoarthritis Pathogenesis: A Review of Molecular Mechanisms
}

\section{Bingjiang Xia,}

Shaoxing Hospital of Traditional Chinese Medicine, Shaoxing 312000, Zhejiang, China; Zhejiang Chinese Medical University, Hangzhou 310053, Zhejiang, China

\section{Di Chen,}

Zhejiang Chinese Medical University, Hangzhou 310053, Zhejiang, China; Department of Biochemistry, Rush University Medical Center, Chicago, IL 60612, USA

\section{Jushi Zhang,}

Shaoxing Hospital of Traditional Chinese Medicine, Shaoxing 312000, Zhejiang, China; Zhejiang Chinese Medical University, Hangzhou 310053, Zhejiang, China

\section{Songfeng Hu,}

Shaoxing Hospital of Traditional Chinese Medicine, Shaoxing 312000, Zhejiang, China; Zhejiang Chinese Medical University, Hangzhou 310053, Zhejiang, China

Hongting Jin, and

Zhejiang Chinese Medical University, Hangzhou 310053, Zhejiang, China; Institute of Orthopaedics and Traumatology, Hangzhou 310053, Zhejiang, China

\section{Peijian Tong}

Zhejiang Chinese Medical University, Hangzhou 310053, Zhejiang, China; Institute of Orthopaedics and Traumatology, Hangzhou 310053, Zhejiang, China

\section{Abstract \\ Osteoarthritis (OA), the most prevalent chronic joint disease, increases in prevalence with age, and affects majority of individuals over the age of 65 and is a leading musculoskeletal cause of impaired mobility in the elderly. Because the precise molecular mechanisms which are involved in the degradation of cartilage matrix and development of OA are poorly understood and there are currently no effective interventions to decelerate the progression of $\mathrm{OA}$ or retard the irreversible degradation of cartilage except for total joint replacement surgery. In this paper, the important molecular mechanisms related to OA pathogenesis will be summarized and new insights into potential molecular targets for the prevention and treatment of OA will be provided.}

xiabj2006@sina.com.

Conflict of Interest Bingjiang Xia, Di Chen, Jushi Zhang, Songfeng Hu, Hongting Jin, and Peijian Tong do not have a commercial interest, financial interest, and/or other relationship with manufacturers of pharmaceuticals, laboratory supplies, and/or medical devices or with commercial providers of medically related services.

Human and Animal Rights and Informed Consent This article does not contain any studies with human or animal subjects performed by any of the authors. 


\section{Keywords}

Osteoarthritis; Molecular mechanisms; Potential therapeutic approches

\section{Introduction}

Osteoarthritis (OA), the most prevalent chronic joint disease, increases in prevalence with age, and affects majority of individuals over the age of $65[1,2]$. A report from the Third National Health and Nutrition Examination Survey reveals that about $37.4 \%$ of adults in the United States who are 60 years of age or older have radiographic evidence of OA [3]. OA most affects the joint including knees, hands, hips, and spine, and is a leading musculoskeletal cause of impaired mobility in the elderly [4, 5]. While several risk factors associated with OA have been put forward, including genetic predisposition, aging, obesity, and joint mal-alignment, the pathogenesis of OA remains largely unclear [6, 7]. The major clinical symptoms include chronic pain, joint instability, stiffness, joint deformities, and radiographic joint space narrowing $[8,9]$. Treatment of osteoarthritis involves alleviating pain, reducing stiffness, maintaining the functional capacities and improving quality of life [8]. Current treatments include low-impact aerobic exercise [10], weight loss [11], acupuncture [12], glucosamine and chondroitin Sulfate [13], and surgical [14]. Because the precise molecular mechanisms which involved in pathogenesis of OA are poorly understood and there are currently no effective interventions to decelerate the progression of OA or retard the irreversible degradation of cartilage except for total joint replacement surgery [15]. The economic burden of osteoarthritis may exceed $\$ 60$ billion per year in the United States [16]. In this paper, the important molecular mechanisms related to OA pathogenesis will be summarized and new insights into potential molecular targets for the prevention and treatment of OA will be provided.

\section{Characteristics of Articular Cartilage}

Articular cartilage is mainly composed of tissue fluid, type II collagen (Col2), and proteoglycans. Of the wet mass, $65-80 \%$ of cartilage is tissue fluid. This high fluid content enables nutrients and oxygen to diffuse through the cartilage matrix to its cells. Collagen type II, and proteoglycans account for 15-22 and 4-7\% of the cartilage wet weight, respectively [17]. Other collagens and proteoglycans such as types V, VI, IX, X, XI, XII, XIV collagens [18] and decorin, biglycan, fibromodulin, lumican, epiphycan, and perlecan [19] also account for a small part (less than $5 \%$ ) of the normal cartilage composition. The articular chondrocyte is the only cell type in articular cartilage and responsible for generating and maintaining the cartilaginous extracellular environment [20, 21].

The collagen/proteoglycan matrix consists of a highly dense meshwork of collagen fibrils including the major collagen type II (Col2) and minor collagen types IX, and XI embedded in gel-like negatively-charged proteoglycans [22]. This hydrated architecture of the matrix provides the articular cartilage with tensile and resilient strength which allows joints to maintain proper biomechanical function [23]. 
As articular cartilage matures, articular chondrocytes maintain the cartilage by synthesizing matrix components (Col2 and proteoglycans) and matrix degrading enzymes with minimal turnover of cells and matrix. The existing collagen network becomes cross-linked, and articular cartilage matures into a permanent tissue with the ability to absorb and respond to mechanical stress [24]. Under normal conditions, articular chondrocytes become arrested at a pre-hypertrophic stage of differentiation, thereby persisting throughout postnatal life to maintain normal articular cartilage structure [25].

\section{Progression of OA}

Articular cartilage can be damaged by normal wear and tear or pathological processes such as abnormal mechanical loading or injury. During the early stages of OA, the cartilage surface is still intact. The molecular composition and organization of the extracellular matrix is altered first [26]. The articular chondrocytes, which possess little regenerative capacity and have a low metabolic activity in normal joints, exhibit a transient proliferative response and increased matrix synthesis (Col2, aggrecan etc.) attempting to initiate repair causing by pathological stimulation. This response is characterized by chondrocyte cloning to form clusters and hypertrophic differentiation, including expression of hypertrophic markers such as Runx2, ColX, and Mmp13. Changes in the composition and structure of the articular cartilage further stimulate chondrocytes to produce more catabolic factors involved in cartilage degradation. As proteoglycans and then the collagen network breakdown [27], cartilage integrity is disrupted. The articular chondrocytes will then undergo apoptosis and the articular cartilage will eventually be completely lost. The reduced joint space resulting from total loss of cartilage will cause friction between bones, leading to pain and limited joint mobility. Other signs of OA, including subchondral sclerosis, bone eburnation, osteophyte formation, as well as loosening and weakness of muscles and tendons will also appear.

\section{Molecular Mechanisms Related to OA Pathogenesis}

The etiology of OA is multi-factorial, including genetic predisposition, aging, obesity, and joint mal-alignment and prior joint injury or surgery [6,7], which can be segregated into categories such as mechanical influences, the effects of aging and genetic factors. Studies show that loss of intact meniscus function leads to OA in humans due to joint instability and abnormal mechanical loading [28, 29]. Recently, the meniscal ligamentous injury (MLI) induced-OA model is becoming a well established mouse model which mimics clinical situation allowing us to study the development and progression of trauma-induced OA on defined genetic backgrounds [30]. In this model, the ligation of the medial collateral ligament coupled with disruption of the meniscus from its anterior-medial attachment can reproducibly induce OA over a 3 month time period. There are rare cases of OA involving mutations of types II, IX, and XI collagen [31, 32]. In addition, there was precious little evidence that inflammatory cytokines such as prostaglandins, TNF-a, interleukin-1, interleukin- 6 and nitric oxide, are important in vivo even though they are potent inducers in vitro [33]. It is well known that genetic factors contribute to the susceptibility for OA. Several studies have demonstrated that molecular mechanisms might be related to the pathogenesis of OA. 


\section{Growth Factors and OA}

TGF- $\beta$-Chondrocyte differentiation and maturation during endochondral ossification are tightly regulated by several key growth factors and transcription factors, including members of the transforming growth factor $\beta$ (TGF- $\beta$ ) super family, fibroblast growth factors (FGFs), Platelet-derived growth factor (PDGF), and parathyroid hormone-related protein (PTHrP) [34-38]. Growth factors have been extensively studied for pathogenesis of OA and cartilage repair because of its ability to enhance matrix synthesis [39].

Since TGF- $\beta$ inhibits chondrocyte hypertrophy and maturation, the inhibition of TGF- $\beta$ signaling represents a potential mechanism in the development of OA [40]. There are three isoforms of TGF- $\beta$, TGF- $\beta 1,2$ and 3 , which can bind to the type II receptor to activate the canonical TGF- $\beta$ /Smad signaling cascade. In the canonical pathway, TGF- $\beta$ binds to the type II receptor which then phosphorylates type I transmembrane serine/threonine kinase receptors. The type I receptor subsequently phosphorylates Smads 2 and 3 (R-Smad) at a conserved SSXS motif at the C-terminus of Smads 2 and 3. The activated R-Smads thus dissociate from the receptor complex and form a heteromeric complex with the common Smad, Smad4. This heteromeric Smad complex then enters the nucleus and associates with other DNA binding proteins to regulate target gene transcription [41].

Loss of TGF- $\beta$ signaling is associated with cartilage damage, which suggesting loss of the protective effect of TGF- $\beta$ during osteoarthritis progression. Additionally, TGF- $\beta$ is involved in early osteophyte formation [40]. In mice, targeted disruption of the TGF- $\beta 1$ gene results in diffuse, and lethal inflammation about 3 weeks after birth and loss of TGF- $\beta 2$ or TGF- $\beta 3$ results in defects in bone development affecting the forelimbs, hindlimbs, and craniofacial bones, suggesting that TGF- $\beta$ plays an important role in skeletogenesis [42].

Recent genetic manipulation of TGF- $\beta$ signaling members also demonstrated that TGF- $\beta$ signaling plays a critical role during OA development. Transgenic mice that over-express the dominant-negative type II TGF- $\beta$ receptor (dnTgfbr2) in skeletal tissue exhibit articular chondrocyte hypertrophy with increased type $\mathrm{X}$ collagen expression, cartilage disorganization and progressive degradation [43]. Consistent with these findings, Smad3 knockout mice show progressive articular cartilage degradation resembling human OA [44]. In order to overcome embryonic lethality and redundancy, we generated chondrocytespecific Tgfbr 2 conditional knockout mice (Tgfbr2 cKO or Tgfbr2Col2CreER mice) in which deletion of the Tgfbr2 gene is mediated by Cre recombinase driven by the chondrocyte-specific Col2a1 promoter in a tamoxifen (TM)-inducible manner [45, 46]. These mice exhibit typical clinical features of OA, including cell cloning, chondrocyte hypertrophy, cartilage surface fibrillation, vertical clefts, and severe articular cartilage damage as well as the formation of chondrophytes and osteophytes [47]. In addition, the relationship between TGF- $\beta$ and OA is strengthened by the discovery that a single nucleotide polymorphism (SNP) in the human Smad3 gene is linked to the incidence of hip and knee $\mathrm{OA}$ in a 527 patient cohort [48].

The TGF- $\beta$ pathway has been identified as a key signaling pathway in osteoarthritis, but evidence for both protective and catabolic roles of TGF- $\beta$ signaling has been reported. Zhen et al. provide new evidence using several models of osteoarthritis to show that TGF- $\beta$ is 
involved in aberrant bone remodeling and cartilage degeneration in osteoarthritis. As increased TGF- $\beta$ activity in the subchondral bone can be a primary cause of osteoarthritis and can initiate pathology, therapeutic targeting may be used to prevent and ease the disease [49].

Loss of TGF- $\beta$ signaling in cartilage induces chondrocyte hypertrophy, eventually leading to cartilage degeneration, and pharmacological activation of the TGF- $\beta$ pathway has therefore been proposed to preserve articular cartilage integrity during osteoarthritis [50]. However, such a strategy exist several caveats, for example, TGF- $\beta$ signaling in chondrocytes seems to switch from the canonical anabolic ALK5-Smad2/3 pathway to the catabolic ALK1-

Smad1/5/8 pathway as they age, suggesting that TGF- $\beta$ supplementation in aged individuals might actually exacerbate cartilage destruction [34].

FGF-2 and FGF-18-Some other growth factors have been described as having a role in the response of cartilage to injury and the development of OA [51]. Of these growth factors, the fibroblast growth factor (FGF) signaling family is known to have several roles [52, 53]. FGF-2 have a potent catabolic and anti-anabolic role in human cartilage homeostasis [54]. FGF-2 is released in supraphysiological amounts during loading and/or injury of the cartilage matrix and activates multiple transduction signal pathways (MAPKs), such as ERK, p38, and JNK [52]. FGF-2 could stimulate MMP-13 expression potently, which is the major degrading enzyme to type II collagen [55]. The FGFR1-Ras/PKC $\delta$-Raf-MEK1/2ERK1/2 signaling pathway is activated after FGF-2 stimulation, which mediates upregulation of matrix-degrading enzyme expression (ADAMTS-5 and MMP-13), as well as down-regulation of aggrecan expression [54, 56-58]. Correspondingly, PKC $\delta$ inhibition significantly impairs these detrimental effects mediated by FGF-2. These findings provide deeper insights into the feasibility of utilizing downstream FGF-2 pathway-specific inhibitors in prevention and/or treatment of degenerative joint diseases. Future focuses may be toward elucidating pharmacological interventions that have a high translational potential and may establish the potential efficacy of a $\mathrm{PKC} \delta$ peptide inhibitor in the treatment of OA [59].

FGF-18, a secreted heparin-binding polypeptide growth factor, has been shown to have a number of functions in different organs [60, 61]. In the musculoskeletal system, FGF-18 is involved in cartilage growth and maturation and is implicated in the development of functional cartilage and bone tissue $[62,63]$. It is also involved in processes within mature cartilage $[62,63]$ as well as being shown to have a role in enhancing regeneration and repair $[64,65]$. Studies have examined the effects of FGF-18 on damaged cartilage. For example, Moore et al. [65] has recently demonstrated that FGF-18 stimulated chondrogenesis and articular cartilage repair in mechanical damage models. And in an in vitro damage/repair model, rhFGF18 increases the proteoglycan synthesis, the repair cell number and prevents apoptosis $[66,67]$. These results indicate that rhFGF18 may be a good candidate growth factor candidate for enhancement of cartilage repair following mechanical damage. 


\section{Wnt, $\beta$-Catenin and OA}

The canonical Wnt/ $\beta$-catenin signaling, which controls multiple developmental processes in skeletal and joint patterning, may also be involved in the progression of OA. When Wnt binds its receptor Frizzled and the co-receptor protein LRP5/6, the signaling protein Disheveled (Dsh) is activated, leading to inactivation of the serine/threonine kinase GSK-3 $\beta$, thus inhibiting the ubiquitination and degradation of $\beta$-catenin. $\beta$-catenin then accumulates in the nucleus and binds LEF-1/TCF to regulate the expression of Wnt target genes. In the absence of the Wnt ligand, cytosolic $\beta$-catenin binds the APC-Axin-GSK- $3 \beta$ degradation complex, and GSK-3 $\beta$ in this complex phosphorylates $\beta$-catenin to induce its proteosomal degradation. The degradation of $\beta$-catenin represses the expression of Wnt responsive genes, allowing binding of the corepressor Groucho to the transcription factors LEF-1/TCF.

In vitro studies show that over-expression of constitutively active $\beta$-catenin leads to loss of the chondrocyte phenotype including reduced Sox 9 and Col2 expression in chick chondrocytes [68]. Genome-wide scans, candidate gene association analyses and single nucleotide polymorphism (SNP) studies have demonstrated the association of hip OA with the Arg324Gly substitution mutation in the sFRP3 protein that antagonizes the binding of Wnt ligands to the Frizzled receptors. The mutation of sFRP3 causes increased levels of active $\beta$-catenin, promoting aberrant articular chondrocyte hypertrophy and thereby leading to hip and knee OA in patients [69-72]. Lories et al. [73] reported that the genetic association between osteoarthritis and FRZB polymorphisms is corroborated by increased cartilage proteoglycan loss in models of arthritis in Frzb(-/-) mice and loss of Frzb may contribute to cartilage damage by increasing the expression and activity of Mmps, in a Wntdependent and Wnt-independent manner. Consistent with this finding, Frzb knockout mice are more sensitive to chemical-induced OA [74].

Since human genetic association studies suggest that $\mathrm{Wnt} / \beta$-catenin signaling may play a critical role in the pathogenesis of OA, we have generated chondrocyte-specific $\beta$-catenin conditional activation (cAct) mice. These mice show high expression of $\beta$-catenin in articular chondrocytes leading to abnormal articular chondrocyte maturation and progressive loss of the articular cartilage surface in 5- and 8-month old mice [75]. The role of Wnt/ $\beta$ catenin signaling in cartilage degeneration is further demonstrated in other animal models. Chondrocyte-specific Col2a1-Smurf2 transgenic mice develop an OA-like phenotype due to up-regulation of $\beta$-catenin caused by Smurf2-induced ubiquitination and degradation of GSK-3 $\beta$ [76]. Furthermore, over-expression of Wnt-induced signaling protein 1 (WISP-1) in the mouse knee joint also leads to cartilage destruction [77]. Consistent with these findings, it has been reported that a panel of Wnt signaling related genes, including WISP-1 and $\beta$ catenin, was significantly up-regulated in knee joints and disc samples from patients with $\mathrm{OA}$ and disc degenerative disease [77]. However, some research reported that inhibition of $\beta$-catenin signaling in articular chondrocytes causes increased cell apoptosis and articular cartilage destruction in Col2a1-ICAT- transgenic mice [78].

The discovery of drugs exerting selective effects on the Wnt/ $\beta$-catenin signaling may help to delimitate the specific roles of this pathway in cartilage degeneration and repair [79]. Recently, a number of antagonists have been identified as the small molecule XAV939, which selectively inhibits $\beta$-catenin-mediated transcription by stabilizing axin [80]. Elevated 
circulating levels of Wnt inhibitor Dickkopf-1 (Dkk-1) are associated with reduced progression of radiologic hip OA in elderly women [81], however, inhibition of this agent results in the bone-forming pattern of OA in animals [82]. Further studies are needed to establish the role of the different components of the Wnt/ $\beta$-catenin pathway and their interaction networks.

\section{Indian Hedgehog (Ihh) and OA}

The Ihh/parathyroid hormone-related protein (PTHrP) negative-feedback loop is critical for chondrocyte differentiation during endochondral bone formation. Articular chondrocytes undergo cellular changes reminiscent of terminal growth plate chondrocyte differentiation during OA [83]. These observations suggest Ihh signaling may play a pivotal role in OA development. Ihh is a major Hh ligand in chondrocytes, which binds with the Patched-1 (PTCH1) receptor to release its inhibition on Smoothened (SMO). SMO can then activate the glioma-associated oncogene homolog (Gli) family of transcription factors to initiate transcription of specific downstream target genes, including Ihh signaling pathway members Gli1, Ptch1 and hedgehog-interacting protein (HHIP).

Immunohistochemical studies demonstrated that Ihh signaling activation positively correlates with the severity of OA in human OA knee joint tissues and high expression of GLI1, PTCH, and HHIP was found in surgically induced murine OA articular cartilage. Activation of Ihh signaling in mice with chondrocyte-specific over-expression of the Gli2 or Smo genes induced a spontaneous OA-like phenotype with high MMP13, ADAMTS5, and ColX expression. In contrast, deletion of the Smo gene or treatment with a pharmacological inhibitor of Ihh attenuated the severity of OA induced by MLI injury [84].

Genetic studies using knockout mice showed that activation of Ihh downstream signaling pathways results in a decrease in articular cartilage thickness and proteoglycan content while inhibiting Ihh signaling results in an increase of articular cartilage thickness and PG [85, 86]. Consistent with these observations, upregulation of hedgehog $(\mathrm{Hh})$ signaling in postnatal cartilage promotes chondrocyte hypertrophy and cartilage degradation [87], suggesting the possibility that blocking Ihh signaling can be used as a therapeutic approach to prevent or delay cartilage degeneration. However, Ihh gene deletion is currently not a therapeutic option as it is lethal in animals. RNA interference (RNAi) provides a means to knockdown Ihh without the severe side effects caused by chemical inhibitors [88]. In the future, it will be necessary to develop a safe and effective RNAi delivery system to target Ihh signaling for preventing and treating OA [89].

\section{HIF-2a and OA}

The HIF proteins, including HIF-1, 2 and 3, are the basic helix-loop-helix transcription factors which function differently under normoxic and hypoxic conditions [90-93]. HIF-1a, in the articular cartilage, acts as an anabolic signal by stimulating specific extracellular matrix synthesis [94,95]. In contrast, HIF-2a (encoded by EPAS1) is a potential catabolic regulator of articular cartilage and induces articular cartilage degeneration [96, 97]. Promoter assays suggest that NF- $\kappa B$ signaling could significantly induce HIF-2a expression and then HIF-2a specifically regulate transcription of several catabolic genes such as 
Mmp13 [96]. Genetic screen using the human osteoarhritic cartilage UniGene library suggests that HIF-2a is a potential catabolic regulator of articular cartilage [97]. Based on the Japanese population ROAD study, a functional SNP in human EPAS1 proximal promoter region was associated with knee osteoarthritis in a 397 patient cohort $[96,98]$. Consistent with this finding, HIF-2a expression was markedly increased in OA patients with degenerative cartilage $[96,97]$. Chondrocyte-specific Epas1 transgenic mice could spontaneously develop osteoarthritis phenotype with increased MMP13 and ColX expression in articular cartilage. In addition, Epas1 heteozygous deficient mice showed resistance to cartilage degeneration induced by meniscus surgery $[96,97]$. Therefore, HIF-2a may be a critical transcription factor that targets several genes for osteoarthritis development.

However, due to the absence of vasculature, the chondrocytes, the only cell type present in the tissue, are appear to have developed specific mechanisms to promote tissue function in response to chronic hypoxia, for example, by inducing increased expression of cartilage matrix components [99-101]. Hypoxia-inducible factors (HIFs) appear to be critical to tissue-specific responses in chondrocytes. Applying the technique of RNA interference, they subsequently demonstrated that HIF-2a was critical for this hypoxic induction of cartilage matrix synthesis in HACs [99]. Furthermore, the main matrix genes, such as those encoding Col-2a1, aggrecan and Col-9 are up-regulated by hypoxia through cartilage-specific transcription factor SOX9. When putative hypoxia response element sequences were mutated, hypoxic induction was abolished. In addition, the specific role of HIFs in this hypoxic induction of chondrogenesis from MSCs deserves further exploration, and interestingly, Hardingham and colleagues have recently shown that human MSCs isolated from the infrapatellar fat pad showed enhanced chondrogenic differentiation in hypoxia, and furthermore, that HIF-2a, but not HIF-1a, was up-regulated in these cultures [102].

However, HIF-2a is a potential therapeutic strategy for the regulation of osteoarthritic cartilage destruction, some caution seems warranted. Most transcription factors are active in multiple cell types and to avoid systemic side effects of a putative inhibitor, local targeting of OA affected joints probably is the preferred way forward [103]. In addition, HIF-2a is primarily expressed in early stages of OA, so therapy should be started at recent onset of OA [104].

\section{GDF-5 and OA}

Growth differentiation factor 5 (GDF-5), which is a member of TGF- $\beta$ superfamily [105], is an extracellular signaling molecule that participates in bone and cartilage morphogenesis as well as in joint formation [106].

A number of studies have demonstrated that GDF-5 plays important roles in musculoskeletal processes, affecting endochondral ossification, synovial joint formation, tendon maintenance, and bone formation [107, 108]. Defects of this gene were shown to be correlated to abnormal joint development or skeletal disorders in humans and mice [109-112]. Mutations in human GDF-5 gene result in a broad spectrum of skeletal disorders [113]. Miyamoto et al. genotyped a number of common GDF-5 polymorphisms and demonstrated that rs 143383 , a $\mathrm{T}$ to $\mathrm{C}$ transition located in the $5^{\prime}$ untranslated region $\left(5^{\prime} \mathrm{UTR}\right)$ 
of the gene, was significantly associated with OA [114]. Further studies have revealed that rs143383 is functional, the OA-associated T-allele mediating reduced GDF-5 transcription relative to the $\mathrm{C}$-allele in all of the joint tissues $[115,116]$, however, some other groups did not confirm these results [117].

Mouse models have provided a basis for better understanding of the role of GDF-5 in skeletogenesis and joint maintenance [109-111]. The brachypodism (bp) mice which carry a functional null allele of GDF-5 caused by a frame-shift mutation, exhibited abnormal skeletal and bone development [118, 119]. However, Gdf5Bp-J/+ mice appeared phenotypically normal, but do show an increased propensity of developing an OA phenotype when challenged [120]. This model suggested that decreased GDF-5 levels in mice contribute to osteoarthritis development. In addition, GDF-5 deficient mice exhibited biomechanical abnormalities in the tendon, which may be associated with altered type I collagen and skeletal abnormalities, one hypothesis of the mechanism behind that was GDF-5 might modulate the rate of endochondral bone growth by affecting the duration of the hypertrophic phase in growth plate chondrocytes [121]. It is supportive of the genetic data indicating the association between GDF-5 and human osteoarthritis, however, it remains unclear why the frequency of the associated alleles varies across studies, identification of functional variants will probably require biological as well as additional genetic assays.

Several studies have reported the use of GDF5 in therapeutics. Bobacz et al. [122] showed an increase in glycosaminoglycan (GAG) synthesis in normal and OA chondrocytes cultured with GDF5, and an increase in ACAN mRNA levels. Chubinskaya et al. [123] observed an increase in GAG synthesis in alginate bead cultures of chondrocytes in the presence of GDF5. However, Ratnayake et al. [124] showed that osteoarthritis chondrocytes do not respond in a predictable manner to culture with exogenous GDF5. This may be a cause or a consequence of the osteoarthritis disease process and will need to be surmounted if treatment with exogenous GDF5 is to be advanced as a potential means to overcome the genetic deficit conferring osteoarthritis susceptibility at this gene [124].

\section{MMP-13, ADAMTS, and OA}

MMP-13 is a substrate-specific enzyme that targets collagen for degradation. Compared to other MMPs, MMP-13 expression is more restricted to connective tissues [125-128]. MMP-13 preferentially cleaves $\mathrm{Col} 2$, which is most abundant in articular cartilage and in the nucleus pulposus, inner anulus fibrosus and cartilage endplate of the intervertebral disc. It also targets the degradation of other proteins in cartilage, such as aggrecan, types IV and IX collagen, gelatin, osteonectin and perlecan [129]. MMP-13 has a much higher catalytic velocity rate compared with other MMPs over Col 2 and gelatin, making it the most potent peptidolytic enzyme among collagenases $[130,131]$.

Clinical investigations revealed that patients with articular cartilage destruction had high MMP-13 expression [132], suggesting increased MMP-13 may be the cause of cartilage degradation. Mmp13 deficient mice show no gross phenotypic abnormalities, and the only alteration is in growth plate architecture during early cartilage development $[133,134]$. However, transgenic mice with cartilage-specific Mmp13-overexpressing develop 
spontaneous articular cartilage destruction characterized by excessive cleavage of Col2 and loss of aggrecan [135].

In the above-mentioned Tgfbr $2 \mathrm{cKO}$ and $\beta$-catenin cAct mouse models, MMP-13 expression is significantly increased $[47,60]$. These findings suggest that MMP-13 deficiency does not affect articular cartilage function during the postnatal and adult stages but abnormal upregulation of MMP-13 can lead to cartilage destruction. Moreover, deletion of the Mmp-13 gene prevents articular cartilage erosion induced by meniscal injury [136].

The ADAMTS family consists of large family members and they share several distinct protein modules as well. Studies show that ADAMTS 4 and 5 expression levels are significantly increased during OA development. Single knockout of the Adamts5 gene or double knockout of the Adamts4 and Adamts5 genes prevents cartilage degradation in surgery-induced and chemical-induced murine knee OA models [137-139]. Interestingly, in Tgfbr 2 cKO, $\beta$-catenin and Ihh activation mouse models, ADAMTS5 was significantly increased in articular cartilage tissue, suggesting that maintaining proper ADAMTS5 levels are essential for normal articular cartilage function. Taken together, these findings indicate that catabolic enzymes play a significant role in OA progression and targeting these enzymes may be a viable therapeutic strategy to decelerate articular cartilage degradation.

Since MMP-13 and ADAMTS5 are two potentially attractive targets for OA therapy, the inhibition of these enzymes and their regulatory mechanisms has been extensively studied. Tissue inhibitors of metalloproteinases (TIMP) are specific inhibitors which directly bind MMPs and ADAMTS in chondrocytes to prevent the destruction of articular cartilage [140]. A specific small molecule MMP-13 inhibitor can attenuate the severity of OA in the MLIinduced injury model as well [141].

In addition to proteinase inhibitors, the transcription factor Runt domain factor-2 (Runx2) appears to be another potential target to regulate MMP-13 and ADAMTS5 in vivo. DNA sequence analysis of Mmp-13 and Adamts5 promoters identified putative Runx 2 binding sites in the promoter regions of these genes. In addition, Runx 2 has an overlapping expression pattern with MMP-13 and ADAMTS5, almost exclusively in the developing cartilage and bone, suggesting that Runx 2 may be an important transcription factor regulating tissue-specific expression of Mmp13 and Adamts5 in articular chondrocytes [142-144]. Thus, manipulation of Runx2 expression in vivo could be an effective therapeutic strategy. During bone development, the temporal and spatial expression patterns of Runx2 are regulated by cytokines and growth factors including TGF- $\beta$, BMP, and FGF [145-148]. In addition to gene expression, Runx 2 protein levels are also regulated through posttranslational mechanisms involving phosphorylation, ubiquitination, and acetylation [149-154]. MicroRNA regulation is another important regulatory mechanism for protein translation. MicroRNA-140 (miR-140) is the first microRNA demonstrated to be involved in the pathogenesis of OA at least partially through regulation of ADAMTS5 mRNA expression. MiR-140 knockout mice are susceptible to age-related OA progression and conversely, over-expression of miR-140 in chondrocytes protects mice from OA development [155-157]. 


\section{Summary}

Articular chondrocyte is the sensor of articular cartilage homeostasis, and plays a critical role in maintaining the normal physiological structure and function of articular cartilage. Recent studies demonstrate that articular chondrocyte homeostasis can be disrupted by multiple factors, including abnormal mechanical loading, and aging. Additionally, genetic alterations in TGF- $\beta / \mathrm{Smad}, \mathrm{Wnt} / \beta$-catenin and Ihh signaling pathways can disrupt the balance between anabolic and catabolic activity in articular cartilage and result in irreversible degradation of the extracellular matrix. Thus far, most of the mouse models of osteoarthritis converge at the up-regulation of catabolic enzymes, such as MMP-13 and ADAMTS5, suggesting that these enzymes may serve as potential therapeutic targets in regulation of the progression of OA. In addition, manipulation of the above-mentioned molecule in articular chondrocytes could also play a role in articular cartilage regeneration.

\section{Acknowledgments}

This publication was made possible by the National Natural Science Foundation of China (Grant No. 81202710), Science Technology Department of Zhejiang Province (Grant Nos. 2011R50022-01, 2012C13017-2), supported by the Program for Zhejiang Leading Team of S\&T Innovation, supported by Key Laboratory of Zhejiang Province, supported by Zhejiang Chinese Medical University.

\section{References}

1. Dahaghin S, Bierma-Zeinstra SM, Ginai AZ, et al. Prevalence and pattern of radiographic hand osteoarthritis and association with pain and disability. Ann Rheum Dis. 2005; 64:682-687. [PubMed: 15374852]

2. Oliveria SA, Felson DT, Reed JI, et al. Incidence of symptomatic hand, hip, and knee osteoarthritis among patients in a health maintenance organization. Arthritis Rheum. 1995; 38:1134-1141. [PubMed: 7639811]

3. Dillon CF, Rasch EK, Gu Q, et al. Prevalence of knee osteoarthritis in the United States: arthritis data from the Third National Health and Nutrition Examination Surgery 1991-94. J Rheumatol. 2006; 33:2271-2279. [PubMed: 17013996]

4. Felson DT. Epidemiology of hip and knee osteoarthritis. Epidemiol Rev. 1988; 10:1-28. [PubMed: 3066625]

5. March LM, Bachmeier CJ. Economics of osteoarthritis: a global perspective. Baillieres Clin Rheumatol. 1997; 11:817-834. [PubMed: 9429738]

6. Rai MF, Sandell LJ. Inflammatory mediators: tracing links between obesity and osteoarthritis. Crit Rev Eukaryot Gene Expr. 2011; 21:131-142. [PubMed: 22077152]

7. Mobasheri A. Osteoarthritis year 2012 in review: biomarkers. Osteoarthr Cartil. 2012; 20(12):14511464. [PubMed: 22842200]

8. Felson DT. Osteoarthritis of the knee. NEJM. 2006; 354:841-848. [PubMed: 16495396]

9. Goldring MB, Goldring SR. Osteoarthritis. J Cel Physiol. 2007; 213:626-634.

10. Ettinger WH Jr, Burns R, Messier SP, et al. A randomized trial comparing aerobic exercise and resistance exercise with a health education program in older adults with knee osteoarthritis: the fitness arthritis and seniors trial (FAST). JAMA. 1997; 277:25-31. [PubMed: 8980206]

11. Messier SP, Loeser RF, Miller GD, et al. Exercise and dietary weight loss in overweight and obese older adults with knee osteoarthritis: the arthritis, diet, and activity promotion trial. Arthritis Rheum. 2004; 50:1501-1510. [PubMed: 15146420]

12. Berman BM, Lao L, Langenberg P, et al. Effectiveness of acupuncture as adjunctive therapy in osteoarthritis of the knee: a randomized, controlled trial. Ann Intern Med. 2004; 141:901-910. [PubMed: 15611487] 
13. Bottegoni C, Muzzarelli RA, Giovannini F, et al. Oral chondroprotection with nutraceuticals made of chondroitin sulphate plus glucosamine sulphate in osteoarthritis. Carbohydr Polym. 2014; 109:126-138. [PubMed: 24815409]

14. Leopold SS. Minimally invasive total knee arthroplasty for osteoarthritis. N Engl J Med. 2009; 360:1749-1758. [PubMed: 19387017]

15. Krasonkutsky S, Samuels J, Abramson SB. Osteoarthritis in 2007. Bull NYU Hosp Jt Dis. 2007; 65:222-228. [PubMed: 17922674]

16. Buckwalter JA, Saltzman C, Brown T. The impact of osteoarthritis: implications for research. Clin Orthop Relat Res. 2004; 427:S6-S15. [PubMed: 15480076]

17. Jackson A, Gu W. Transport properties of cartilaginous tissues. Curr Rheumatol Rev. 2009; 5:40. [PubMed: 20126303]

18. Eyre DR, Wu JJ, Fermandes RJ, et al. Recent developments in cartilage research: matrix biology of the collagen II/IX/XI heterofibril network. Biochem Soc Trans. 2002; 30:893-899. [PubMed: 12440941]

19. Knudson CB, Knudson W. Cartilage proteoglycans. Semin Cell Dev Biol. 2001; 12:69-78. [PubMed: 11292372]

20. Woods A, Wang G, Beier F. Regulation of chondrocyte differentiation by the actin cytoskeleton and adhesive interactions. J Cell Physiol. 2007; 213:1-8. [PubMed: 17492773]

21. Goldring MB, Marcu KB. Cartilage homeostasis in health and rheumatic diseases. Arthritis Res Ther. 2009; 11:224. [PubMed: 19519926]

22. Kannu P, Bateman JF, Belluoccio D. Employing molecular genetics of chondrodysplasias to inform the study of osteoarthritis. Arthritis Rheum. 2009; 60:325-334. [PubMed: 19180483]

23. Iozzo, RV. Proteoglycans: structure, biology and molecular interactions. 1st. Thomas Jefferson University, Jefferson Medical College; Philadelphia: 2000.

24. Verzijl N, DeGroot J, Thorpe SR. Effect of collagen turnover on the accumulation of advanced glycation end products. J Biol Chem. 2000; 275:39027-39031. [PubMed: 10976109]

25. Pacifici M, Koyama E, Iwamoto M. Mechanisms of synovial joint and articular cartilage formation: recent advances, but many lingering mysteries. Birth Defects Res. 2005; 75:237-248.

26. Goldring MB, Goldring SR. Articular cartilage and subchondral bone in the pathogenesis of osteoarthritis. Ann NY Acad Sci. 2010; 1192:230-237. [PubMed: 20392241]

27. Mort JS, Billington CJ. Articular cartilage and changes in arthritis matrix degradation. Arthritis Res. 2001; 3:337-341. [PubMed: 11714387]

28. Ding CH, Martel-Pelletier J, Pelletier JP, et al. Meniscal tear as an osteoarthritis risk factor in a largely non-osteoarthritic cohort: a cross-sectional study. J Rheumatol. 2007; 34:776-784. [PubMed: 17361984]

29. Hunter DJ, Zhang YQ, Niu JB, et al. The association of meniscal pathologic changes with cartilage loss in symptomatic knee osteoarthritis. Arthritis Rheum. 2006; 54:795-801. [PubMed: 16508930]

30. Clements KM, Price JS, Chambers MG, et al. Gene deletion of either interleukin-1beta, interleukin-1beta-converting enzyme, inducible nitric oxide synthase, or stromelysin 1 accelerates the development of knee osteoarthritis in mice after surgical transaction of the medial collateral ligament and partial medial meniscectomy. Arthritis Rheum. 2003; 48:3452-3463. [PubMed: 14673996]

31. Li Y, Xu L, Olsen BR. Lessons from genetic forms of osteoarthritis for the pathogenesis of the disease. Osteoarthr Cartil. 2007; 15:1101-1105. [PubMed: 17572112]

32. Kannu P, Bateman JF, Belluoccio D, et al. Employing molecular genetics of chondrodysplasias to inform the study of osteoarthritis. Arthritis Rheum. 2009; 60:325-334. [PubMed: 19180483]

33. Wojdasiewicz P, Poniatowski ŁA, Szukiewicz D. The role of inflammatory and anti-inflammatory cytokines in the pathogenesis of osteoarthritis. Mediat Inflamm. 2014; 2014:561459.

34. van der Kraan PM, Goumans MJ, Blaney Davidson E, et al. Age-dependent alteration of TGF- $\beta$ signalling in osteoarthritis. Cell Tissue Res. 2012; 347:257-265. [PubMed: 21638205]

35. Kolpakova E, Olsen BR. Wnt/beta-catenin-a canonical tale of cell-fate choice in the vertebrate skeleton. Dev Cell. 2005; 8:626-627. [PubMed: 15866155] 
36. Komori T. Requisite roles of Runx 2 and Cbfb in skeletal development. J Bone Miner Metab. 2003; 21:193-197. [PubMed: 12811622]

37. Kronenberg HM. Developmental regulation of the growth plate. Nature. 2003; 423:332-336. [PubMed: 12748651]

38. Degnin CR, Laederich MB, Horton WA. FGFs in endochondral skeletal development. J Cell Biochem. 2010; 110:1046-1057. [PubMed: 20564212]

39. Schmidt MB, Chen EH, Lynch SE. A review of the effects of insulin-like growth factor and platelet derived growth factor on in vivo cartilage healing and repair. Osteoarthr Cartil. 2006; 14:403-412. [PubMed: 16413799]

40. Blaney Davidson EN, Vitters EL, van der Kraan PM, et al. Expression of transforming growth factor- $\beta$ (TGF- $\beta$ ) and the TGF- $\beta$ signalling molecule SMAD- $2 \mathrm{P}$ in spontaneous and instabilityinduced osteoarthritis: role in cartilage degradation, chondrogenesis and osteophyte formation. Ann Rheum Dis. 2006; 65:1414-1421. [PubMed: 16439443]

41. Miyazawa K, Shinozaka M, Hara T, et al. Two major Smad pathways in TFG- $\beta$ superfamily signaling. Genes Cells. 2002; 7:1191-1204. [PubMed: 12485160]

42. Nicole D, Kerstin K. Targeted mutations of transforming growth factor- $\beta$ genes reveal important roles in mouse development and adult homeostasis. Eur J Bioche. 2000; 267:6982-6988.

43. Serra R, Johnson M, Filvaroff EH, et al. Expression of a truncated, kinase-defective TGF-b type II receptor in mouse skeletal tissue promotes terminal chondrocyte differentiation and osteoarthritis. J Cell Biol. 1997; 139:541-552. [PubMed: 9334355]

44. Yang X, Chen L, Xu X, et al. TGF- $\beta /$ Smad3 signals repress chondrocyte hypertrophic differentiation and are required for maintaining articular cartilage. J Cell Biol. 2001; 153:35-46. [PubMed: 11285272]

45. Chen M, Lichtler AC, Sheu T, et al. Generation of a transgenic mouse model with chondrocytespecific and tamoxifen-inducible expression of Cre recombinase. Genesis. 2007; 45:44-50. [PubMed: 17211877]

46. Zhu M, Chen M, Lichlter AC, et al. Tamoxifen-inducible Cre-recombination in articular chondrocytes of adult Col2a1-CreERT2 transgenic mice. Osteoarthr Cartil. 2008; 16:129-130. [PubMed: 17888690]

47. Shen J, Li J, Wang B, et al. Deletion of the transforming growth factor $\beta$ receptor type II gene in articular chondrocytes leads to a progressive osteoarthritis-like phenotype in mice. Arthritis Rheum. 2013; 65:3107-3119. [PubMed: 23982761]

48. Valdes AM, Spector TD, Tamm A, et al. Genetic variation in the smad3 gene is associated with hip and knee osteoarthritis. Arthritis Rheum. 2010; 62:2347-2352. [PubMed: 20506137]

49. Zhen G, Wen C, Jia X, et al. Inhibition of TGF- $\beta$ signaling in mesenchymal stem cells of subchondral bone attenuates osteoarthritis. Nat Med. 2013; 19:704-712. [PubMed: 23685840]

50. Blaney Davidson EN, van der Kraan PM, van den Berg WB. TGF-ßeta and osteoarthritis. Osteoarthritis Cartilage. 2007; 15:597-604. [PubMed: 17391995]

51. Fortier LA, Barker JU, Strauss EJ, et al. The role of growth factors in cartilage repair. Clin Orthop Relat Res. 2011; 469:2706-2715. [PubMed: 21403984]

52. Chia SL, Sawaji Y, Burleigh A, et al. Fibroblast growth factor 2 is an intrinsic chondroprotective agent that suppresses ADAMTS-5 and delays cartilage degradation in murine osteoarthritis. Arthritis Rheum. 2009; 60:2019-2027. [PubMed: 19565481]

53. Cucchiarini M, Terwilliger EF, Kohn D, et al. Remodelling of human osteoarthritic cartilage by FGF-2, alone or combined with Sox9 via rAAV gene transfer. J Cell Mol Med. 2009; 13:24762488. [PubMed: 18705695]

54. Li X, Ellman MB, Kroin JS, et al. Species-specific biological effects of FGF-2 in articular cartilage: implication for distinct roles within the FGF receptor family. J Cell Biochem. 2012; 113:2532-2542. [PubMed: 22415882]

55. Im HJ, Muddasani P, Natarajan V, et al. Basic fibroblast growth factor stimulates matrix metalloproteinase-13 via the molecular cross-talk between the mitogen-activated protein kinases and protein kinase c pathways in human adult articular chondrocytes. J Biol Chem. 2007; 282:11110-11121. [PubMed: 17311929] 
56. Ellman MB, An HS, Muddasani P, et al. Biological impact of the fibroblast growth factor family on articular cartilage and intervertebral disc homeostasis. Gene. 2008; 420:82-89. [PubMed: 18565695]

57. Ellman M, Kim J, An H, et al. The pathophysiological role of the PKC $\delta$ pathway in the intervertebral disc: in vitro, ex vivo and in vivo studies. Arthritis Rheum. 2011; 64:1950-1959. [PubMed: 22161873]

58. Yan D, Chen D, Im HJ. Fibroblast growth factor-2 promotes catabolism via FGFR1-Ras-RafMEK1/2-ERK1/2 axis that coordinates with the PKC $\delta$ pathway in human articular chondrocytes. J Cell Biochem. 2012; 113:2856-2865. [PubMed: 22488450]

59. Andrew SL, Michael BE, Dongyao Y, et al. A current review of molecular mechanisms regarding osteoarthritis and pain. Gene. 2013; 527:440-447. [PubMed: 23830938]

60. Maruoka Y, Ohbayashi N, Hoshikawa M, et al. Comparison of the expression of three highly related genes, Fgf8, Fgf17 and Fgf18, in the mouse embryo. Mech Dev. 1998; 74:175-177. [PubMed: 9651520]

61. Usui H, Shibayama M, Ohbayashi N, et al. FGF18 is required for embryonic lung alveolar development. Biochem Biophys Res Comm. 2004; 322:887-892. [PubMed: 15336546]

62. Davidson D, Blanc A, Filion D. Fibroblast growth factor (FGF) 18 signals through FGF receptor 3 to promote chondrogenesis. J Biol Chem. 2005; 280:20509-20515. [PubMed: 15781473]

63. Liu Z, Lavine KJ, Hung IH, et al. FGF18 is required for early chondrocyte proliferation, hypertrophy and vascular invasion of the growth plate. Dev Biol. 2007; 302:80-91. [PubMed: 17014841]

64. Carli A, Gao C, Khayyat-Kholghi M, et al. FGF 18 augments osseointegration of intra-medullary implants in osteopenic FGFR3(-/-) mice. Eur Cell Mater. 2012; 24:116-117.

65. Moore EE, Bendele AM, Thompson DL, et al. Fibroblast growth factor-18 stimulates chondrogenesis and cartilage repair in a rat model of injury-induced osteoarthritis. Osteoarthritis Cartilage. 2005; 13:623-631. [PubMed: 15896984]

66. Power J, Hernandez P, Guehring H, et al. Intraarticular injection of rhFGF-18 improves the healing in microfracture treated chondral defects in an ovine model. J Orthop Res. 2014; 32:669-676. [PubMed: 24436147]

67. Barr L, Getgood A, Guehring H, et al. The effect of recombinant human fibroblast growth factor-18 on articular cartilage following single impact load. J Orthop Res. 2014; 32:923-927. [PubMed: 24719286]

68. Geetha-Loganathan P, Nimmagadda S, Scaal M. Wnt signaling in limb organogenesis. Organogenesis. 2008; 4:109-115. [PubMed: 19279722]

69. Loughlin J, Mustafa Z, Smith A, et al. Linkage analysis of chromosome 2q in osteoarthritis. Rheumatology. 2000; 39:377-381. [PubMed: 10817769]

70. Loughlin J, Dowling B, Chapman K, et al. Functional variants within the secreted frizzled-related protein 3 gene are associated with hip osteoarthritis in females. Proc Natl Acad Sci USA. 2004; 101:9757-9762. [PubMed: 15210948]

71. Valdes AM, Doherty S, Muir KR, et al. Genetic contribution to radiographic severity in osteoarthritis of the knee. Ann Rheum Dis. 2012; 71:1537-1540. [PubMed: 22615457]

72. Min JL, Meulenbelt I, Riyazi N, et al. Association of the Frizzled-related protein gene with symptomatic osteoarthritis at multiple sites. Arthritis Rheum. 2005; 52:1077-1080. [PubMed: 15818669]

73. Lories RJ, Peeters J, Bakker A, et al. Articular cartilage and biomechanical properties of the long bones in Frzb-knockout mice. Arthritis Rheum. 2007; 56:4095-4103. [PubMed: 18050203]

74. Lodewyckx L, Cailotto F, Thysen S, et al. Tight regulation of wingless-type signaling in the articular cartilage subchondral bone biomechanical unit: transcriptomics in Frzb-knockout mice. Arthritis Res Ther. 2012; 14:R16. [PubMed: 22264237]

75. Zhu M, Tang D, Wu Q, et al. Activation of $\beta$-catenin signaling in articular chondrocytes leads to osteoarthritis-like phenotype in adult $\beta$-catenin conditional activation mice. J Bone Miner Res. 2009; 24:12-21. [PubMed: 18767925] 
76. Wu Q, Huang JH, Sampson ER, et al. Smurf2 induces degradation of GSK-3 $\beta$ and upregulates $\beta$ catenin in chondrocytes: a potential mechanism for Smurf2-induced degeneration of articular cartilage. Exp Cell Res. 2009; 315:2386-2398. [PubMed: 19481076]

77. Blom AB, Brockbank SM, van Lent PL, et al. Involvement of the Wnt signaling pathway in experimental and human osteoarthritis: prominent role of Wnt-induced signaling protein 1. Arthritis Rheum. 2009; 60:501-512. [PubMed: 19180479]

78. Zhu M, Chen M, Zuscik M, et al. Inhibition of beta-catenin signaling in articular chondrocytes results in articular cartilage destruction. Arthritis Rheum. 2008; 58:2053-2064. [PubMed: 18576323]

79. Alcaraz MJ, Megías J, García-Arnandis I, et al. New molecular targets for the treatment of osteoarthritis. Biochem Pharmacol. 2010; 80:13-21. [PubMed: 20206140]

80. Huang SM, Mishina YM, Liu S, et al. Tankyrase inhibition stabilizes axin and antagonizes Wnt signalling. Nature. 2009; 461:614-620. [PubMed: 19759537]

81. Lane NE, Nevitt MC, Lui LY, et al. Wnt signaling antagonists are potential prognostic biomarkers for the progression of radiographic hip osteoarthritis in elderly Caucasian women. Arthritis Rheum. 2007; 56:3319-3325. [PubMed: 17907185]

82. Diarra D, Stolina M, Polzer K, et al. Dickkopf-1 is a master regulator of joint remodeling. Nat Med. 2007; 13:156-163. [PubMed: 17237793]

83. Tamamura Y, Otani T, Kanatani N, et al. Developmental regulation of Wnt/beta-catenin signals is required for growth plate assembly, cartilage integrity, and endochondral ossification. J Biol Chem. 2005; 280:19185-19195. [PubMed: 15760903]

84. Lin AC, Seeto BL, Bartoszko JM, et al. Modulating hedgehog signaling can attenuate the severity of osteoarthritis. Nat Med. 2009; 15:1421-1426. [PubMed: 19915594]

85. Mak KK, Kronenberg HM, Chuang P-T, et al. Indian hedgehog signals independently of PTHrP to promote chondrocyte hypertrophy. Development. 2008; 135:1947-1956. [PubMed: 18434416]

86. Beaupre GS, Stevens SS, Carter DR. Mechanobiology in the development, maintenance, and degeneration of articular cartilage. J Rehabil Res Dev. 2000; 37:145-151. [PubMed: 10850820]

87. Lin AC, Seeto BL, Bartoszko JM, et al. Modulating hedgehog signaling can attenuate the severity of osteoarthritis. Nat Med. 2009; 15:1421-1425. [PubMed: 19915594]

88. Takahiro, Ushijima; Ken, Okazaki; Hidetoshi, Tsushima, et al. CCAAT/enhancer binding protein $\beta$ regulates expression of Indian Hedgehog during chondrocytes differentiation. PLoS ONE. 2014; 9:e104547. [PubMed: 25105964]

89. Zhou J, Wei X, Wei L. Indian Hedgehog, a critical modulator in osteoarthritis, could be a potential therapeutic target for attenuating cartilage degeneration disease. Connect Tissue Res. 2014; 55:257-261. [PubMed: 24844414]

90. Semenza GL. Regulation of metabolism by hypoxia-inducible factor 1. Cold Spring Harb Symp Quant Biol. 2011; 76:347-353. [PubMed: 21785006]

91. Lando D, Peet DJ, Whelan DA, et al. Asparagine hydroxylation of the HIF transactivation domain a hypoxic switch. Science. 2002; 295:858-861. [PubMed: 11823643]

92. Bracken CP, Whitelaw ML, Peet DJ. The hypoxia-inducible factors: key transcriptional regulators of hypoxic responses. Cell Mol Life Sci. 2003; 60:1376-1393. [PubMed: 12943226]

93. Kiss J, Kirchberg J, Schneider M. Molecular oxygen sensing: implications for visceral surgery. Langenbecks Arch Surg. 2012; 397(4):603-610. [PubMed: 22395314]

94. Duval E, Leclercq S, Elissalde JM, et al. Hypoxia-inducible factor 1alpha inhibits the fibroblastlike markers type I and type III collagen during hypoxia-induced chondrocyte redifferentiation: hypoxia not only induces type II collagen and aggrecan, but it also inhibits type I and type III collagen in the hypoxia-inducible factor 1 alpha-dependent redifferentiation of chondrocytes. Arthritis Rheum. 2009; 60:3038-3048. [PubMed: 19790048]

95. Pfander D, Cramer T, Schipani E, et al. HIF-1alpha controls extracellular matrix synthesis by epiphyseal chondrocytes. J Cell Sci. 2003; 116:1819-1826. [PubMed: 12665562]

96. Saito T, Fukai A, Mabuchi A, et al. Transcriptional regulation of endochondral ossification by HIF-2alpha during skeletal growth and osteoarthritis development. Nat Med. 2010; 16:678-686. [PubMed: 20495570] 
97. Yang S, Kim J, Ryu JH, et al. Hypoxia-inducible factor-2alpha is a catabolic regulator of osteoarthritic cartilage destruction. Nat Med. 2010; 16:687-693. [PubMed: 20495569]

98. Muraki S, Oka H, Akune T, et al. Prevalence of radiographic knee osteoarthritis and its association with knee pain in the elderly of Japanese population-based cohorts: the ROAD study. Osteoarthr Cartil. 2009; 17:1137-1143. [PubMed: 19410032]

99. Lafont JE, Talma S, Murphy CL. Hypoxia-inducible factor 2alpha is essential for hypoxic induction of the human articular chondrocyte phenotype. Arthritis Rheum. 2007; 56:3297-3306. [PubMed: 17907154]

100. Lafont JE, Talma S, Hopfgarten C, et al. Hypoxia promotes the differentiated human articular chondrocyte phenotype through SOX9-dependent and -independent pathways. J Biol Chem. 2008; 283:4778-4786. [PubMed: 18077449]

101. Domm C, Schunke M, Christesen K, et al. Redifferentiation of dedifferentiated bovine articular chondrocytes in alginate culture under low oxygen tension. Osteoarthr Cartil. 2002; 10:13-22. [PubMed: 11795979]

102. Khan WS, Adesida AB, Hardingham TE. Hypoxic conditions increase hypoxia-inducible transcription factor 2alpha and enhance chondrogenesis in stem cells from the infrapatellar fat pad of osteoarthritis patients. Arthritis Res Ther. 2007; 9:R55. [PubMed: 17537234]

103. van den Berg WB. Osteoarthritis year 2010 in review: pathomechanisms. Osteoarthr Cartil. 2011; 19:338-341. [PubMed: 21324370]

104. Wang M, Shen J, Jin H, et al. Recent progress in understanding molecular mechanisms of cartilage degeneration during osteoarthritis. Ann NY Acad Sci. 2011; 1240:61-69. [PubMed: 22172041]

105. Buxton P, Edwards C, Archer CW, et al. Growth/differentiation factor-5 (GDF-5) and skeletal development. J Bone Joint Surg Am. 2001; 83:23-30.

106. Francis-West PH, Abdelfattah A, Chen P, et al. Mechanisms of GDF-5 action during skeletal development. Development. 1999; 126:1305-1315. [PubMed: 10021348]

107. Nishitoh H, Ichijo H, Kimura M. Identification of type I and type II serine/threonine kinase receptors for growth/differentiation factor-5. J Biol Chem. 1996; 271:21345-21352. [PubMed: 8702914]

108. Mikic B, Battaglia TC, Taylor EA. The effect of growth/differentiation factor-5 deficiency on femoral composition and mechanical behavior in mice. Bone. 2002; 30:733-737. [PubMed: 11996912]

109. Masuya H, Nishida K, Furuichi T, et al. A novel dominant-negative mutation in Gdf5 generated by ENU mutagenesis impairs joint formation and causes osteoarthritis in mice. Hum Mol Genet. 2007; 16:2366-2375. [PubMed: 17656374]

110. Chhabra A, Tsou D, Clark RT, et al. GDF-5 deficiency in mice delays Achilles tendon healing. J Orthop Res. 2003; 21:826-835. [PubMed: 12919870]

111. Harada M, Takahara M, Zhe P, et al. Developmental failure of the intra-articular ligaments in mice with absence of growth differentiation factor 5. Osteoarthr Cartil. 2007; 15:468-474. [PubMed: 17052922]

112. Nickel J, Kotzsch A, Sebald W. A single residue of GDF-5 defines binding specificity to BMP receptor IB. J Mol Biol. 2005; 349:933-947. [PubMed: 15890363]

113. Byrnes AM, Racacho L, Nikkel SM, et al. Mutations in GDF5 presenting as semidominant brachydactyly A1. Hum Mutat. 2010; 31:1155-1162. [PubMed: 20683927]

114. Miyamoto Y, Mabuchi A, Shi D, et al. A functional polymorphism in the $5^{\prime}$-UTR of GDF5 is associated with susceptibility to osteoarthritis. Nat Genet. 2007; 39:529-533. [PubMed: 17384641]

115. Byrnes AM, Racacho L, Nikkel SM, et al. Mutations in GDF5 presenting as semidominant brachydactyly A1. Hum Mutat. 2010; 31:1155-1162. [PubMed: 20683927]

116. Egli R, Southam L, Wilkins JM, et al. Functional analysis of the osteoarthritis susceptibilityassociated GDF5 regulatory polymorphism. Arthritis Rheum. 2009; 60:2055-2064. [PubMed: 19565498] 
117. Tsezou A, Satra M, Oikonomou P, et al. The growth differentiation factor 5 (GDF5) core promoter polymorphism is not associated with knee osteoarthritis in the Greek population. $\mathrm{J}$ Orthop Res. 2008; 26:136-140. [PubMed: 17676627]

118. Storm EE, Huynh TV, Copeland NG, et al. Limb alterations in brachypodism mice due to mutations in a new member of the TGFb-superfamily. Nature. 1994; 368:639-643. [PubMed: 8145850]

119. Takahara M, Harada M, Guan D, et al. Developmental failure of phalanges in the absence of growth/differentiation factor 5. Bone. 2004; 35:1069-1076. [PubMed: 15542031]

120. Daans M, Luyten FP, Lories RJ. GDF5 deficiency in mice is associated with instability-driven joint damage, gait and subchondral bone changes. Ann Rheum Dis. 2011; 70:208-213. [PubMed: 20805298]

121. Mikic B, Clark RT, Battaglia TC. Altered hypertrophic chondrocyte kinetics in GDF-5 deficient murine tibial growth plates. J Orthop Res. 2004; 22:552-556. [PubMed: 15099634]

122. Bobacz K, Gruber R, Soleiman A, et al. Cartilage-derived morphogenetic protein-1 and -2 are endogenously expressed in healthy and osteoarthritic human articular chondrocytes and stimulate matrix synthesis. Osteoarthr Cartil. 2002; 10:394-401. [PubMed: 12027540]

123. Chubinskaya S, Segalite D, Pikovsky D, et al. Effects induced by BMPs in cultures of human articular chondrocytes: comparative studies. Growth Factors. 2008; 26:275-283. [PubMed: 18651287]

124. Ratnayake M, Plöger F, Santibanez-Koref M, et al. Human chondrocytes respond discordantly to the protein encoded by the osteoarthritis susceptibility gene GDF5. PLoS ONE. 2014; 9:e86590. [PubMed: 24466161]

125. Borden P, Heller RA. Transcriptional control of matrix metalloproteinases and the tissue inhibitors of matrix metalloproteinases. Crit Rev Eukaryot Gene Expr. 1997; 7:159-178. [PubMed: 9034720]

126. Mengshol JA, Vincenti MP, Coon CI. Interleukin-1 induction of collagenase 3 (matrix metalloproteinase 13) gene expression in chondrocytes requires p38, c-Jun N-terminal kinase, and nuclear factor kappaB: differential regulation of collagenase 1 and collagenase 3 . Arthritis Rheum. 2000; 43:801-811. [PubMed: 10765924]

127. Vincenti MP, Coon CI, Mengshol JA, et al. Cloning of the gene for interstitial collagenase-3 (matrix metalloproteinase-13) from rabbit synovial fibroblasts: differential expression with collagenase-1 (matrix metalloproteinase-1). Biochem J. 1998; 331:341-346. [PubMed: 9512498]

128. Vincenti MP. The matrix metalloproteinase (MMP) and tissue inhibitor of metalloproteinase (TIMP) genes. Transcriptional and posttranscriptional regulation, signal transduction and celltype-specific expression. Methods Mol Biol. 2001; 151:121-148. [PubMed: 11217296]

129. Shiomi T, Lemaître V, D'Armiento J, et al. Matrix metalloproteinases, a disintegrin and metalloproteinases, and a disintegrin and metalloproteinases with thrombospondin motifs in nonneoplastic diseases. Pathol Int. 2010; 60:477-496. [PubMed: 20594269]

130. Knäuper V, Lopez Otin C, Smith B, Knight G. Biochemical characterization of human collagenase-3. J Biol Chem. 1996; 271:1544-1550. [PubMed: 8576151]

131. Walling HW, Raggatt LJ, Irvine DW, et al. Impairment of the collagenase-3 endocytotic receptor system in cells from patients with osteoarthritis. Osteoarthr Cartil. 2003; 11:854-863. [PubMed: 14629961]

132. Roach HI, Yamada N, Cheung KS, et al. Association between the abnormal expression of matrixdegrading enzymes by human osteoarthritic chondrocytes and demethylation of specific CpG sites in the promoter regions. Arthritis Rheum. 2005; 52:3110-3124. [PubMed: 16200590]

133. Inada M, Wang Y, Byrne MH, et al. Critical roles for collagenase-3 (Mmp13) in development of growth plate cartilage and in endochondral ossification. Proc Natl Acad Sci USA. 2004; 101:17192-17197. [PubMed: 15563592]

134. Stickens D, Behonick DJ, Ortega N, et al. Altered endochondral bone development in matrix metalloproteinase 13-deficient mice. Development. 2004; 131:5883-5895. [PubMed: 15539485]

135. Neuhold LA, Killar L, Zhao W, et al. Postnatal expression in hyaline cartilage of constitutively active human collagenase-3 (MMP-13) induces osteoarthritis in mice. J Clin Investig. 2001; 107:35-44. [PubMed: 11134178] 
136. Little CB, Barai A, Burkhardt D, et al. Matrix metalloproteinase 13-deficient mice are resistant to osteoarthritic cartilage erosion but not chondrocyte hypertrophy or osteophyte development. Arthritis Rheum. 2009; 60:3723-3733. [PubMed: 19950295]

137. Glasson SS, Askew R, Sheppard B, et al. Deletion of active ADAMTS5 prevents cartilage degradation in a murine model of osteoarthritis. Nature. 2005; 434:644-648. [PubMed: 15800624]

138. Majumdar MK, Askew R, Schelling S, et al. Double-knockout of ADAMTS-4 and ADAMTS-5 in mice results in physiologically normal animals and prevents the progression of osteoarthritis. Arthritis Rheum. 2007; 56:3670-3674139. [PubMed: 17968948]

139. Stanton H, Rogerson FM, East CJ, et al. ADAMTS5 is the major aggrecanase in mouse cartilage in vivo and in vitro. Nature. 2005; 434:648-652. [PubMed: 15800625]

140. Stetler Stevenson WG, Seo DW. TIMP-2: an endogenous inhibitor of angiogenesis. Trends in molecular medicine. 2005; 11:97-103. [PubMed: 15760767]

141. Wang M, Sampson ER, Jin H, et al. MMP13 is a critical target gene during the progression of osteoarthritis. Arthritis Res Ther. 2013; 15:R5. [PubMed: 23298463]

142. Enomoto H, Enomoto Iwamoto M, Iwamoto M, et al. Cbfa1 is a positive regulatory factor in chondrocyte maturation. J Biol Chem. 2000; 275:8695-8702. [PubMed: 10722711]

143. Inada M, Yasui T, Nomura S, et al. Maturational disturbance of chondrocytes in Cbfa1-deficient mice. Dev Dyn. 1999; 214:279-290. [PubMed: 10213384]

144. Komori T, Yagi H, Nomura S, et al. Targeted disruption of Cbfa1 results in a complete lack of bone formation owing to maturational arrest of osteoblasts. Cell. 1997; 89:755-764. [PubMed: 9182763]

145. Kim HJ, Kim JH, Bae SC, et al. The protein kinase C pathway plays a central role in the fibroblast growth factorstimulated expression and transactivation activity of Runx2. J Biol Chem. 2003; 278:319-326. [PubMed: 12403780]

146. Takamoto M, Tsuji K, Yamashita T, et al. Hedgehog signaling enhances core-binding factor a1 and receptor activator of nuclear factor-kappaB ligand (RANKL) gene expression in chondrocytes. J Endocrinol. 2003; 177:413-421. [PubMed: 12773122]

147. Tou L, Quibria N, Alexander JM. Regulation of human cbfa1 gene transcription in osteoblasts by selective estrogen receptor modulators (SERMs). Mol Cell Endocrinol. 2001; 183:71-79. [PubMed: 11604227]

148. Zhou YX, Xu X, Chen L, et al. A Pro250Arg substitution in mouse Fgfr1 causes increased expression of Cbfa1 and premature fusion of calvarial sutures. Hum Mol Genet. 2000; 9:20012008. [PubMed: 10942429]

149. Zhao M, Qiao M, Harris SE, et al. E3 ubiquitin ligase Smurf1 mediates core-binding factor alpha 1/Runx2 degradation and plays a specific role in osteoblast differentiation. J Biol Chem. 2003; 278:27939-27944. [PubMed: 12738770]

150. Zhao M, Qiao M, Harris SE, et al. Smurf1 inhibits osteoblast differentiation and bone formation in vitro and in vivo. J Biol Chem. 2004; 279:12854-12859. [PubMed: 14701828]

151. Shen R, Chen M, Wang YJ, et al. Smad6 interacts with Runx2 and mediates Smad ubiquitin regulatory factor 1-induced Runx2 degradation. J Biol Chem. 2006; 281:3569-3576. [PubMed: 16299379]

152. Shen R, Wang X, Drissi H, et al. Cyclin D1-cdk4 induce runx2 ubiquitination and degradation. J Biol Chem. 2006; 281:16347-16353. [PubMed: 16613857]

153. Jeon EJ, Lee KY, Choi NS, et al. Bone morphogenetic protein-2 stimulates Runx2 acetylation. J Biol Chem. 2006; 281:16502-16511. [PubMed: 16613856]

154. Jonason JH, Xiao G, Zhang M, et al. Post-transcriptional regulation of runx 2 in bone and cartilage. J Dent Res. 2009; 88:693-703. [PubMed: 19734454]

155. Akhtar N, Rasheed Z, Ramamurthy S, et al. MicroRNA-27b regulates the expression of MMP-13 in human osteoarthritis chondrocytes. Arthritis Rheum. 2010; 62:1361-1371. [PubMed: 20131257]

156. Miyaki S, Nakasa T, Otsuki S, et al. MicroRNA-140 is expressed in differentiated human articular chondrocytes and modulates interleukin-1 responses. Arthritis Rheum. 2009; 60:27232730. [PubMed: 19714579] 
157. Yamasaki K, Nakasa T, Miyaki S, et al. Expression of microRNA-146a in osteoarthritis cartilage. Arthritis Rheum. 2009; 60:1035-1041. [PubMed: 19333945] 